\section{A Novel Method to Quantify Transport of Self- and Cross-pollen by Bees in Blueberry Plantings}

\author{
Patricio A. Brevis ${ }^{1}$ \\ Department of Horticulture, Michigan State University, A316 Plant and Soil \\ Science Building, East Lansing, MI 48824-1325
}

D. Scott NeSmith ${ }^{2}$

Department of Horticulture, University of Georgia, Griffin Campus, Griffin, GA 30223

Lynne Seymour
Department of Statistics, University of Georgia, Athens, GA 30602

Dorothy B. Hausman ${ }^{4}$

Department of Foods and Nutrition, University of Georgia, Athens, GA 30602

Additional index words. Ericaceae, rabbiteye blueberry, pollen dispersion, tetrad

Abstract. Blueberry species (Vaccinium section Cyanococcus) benefit from cross-pollination. Outcrossing increases fruit set, berry size, and ripening rate. Although knowledge of pollen dispersal is essential for maximizing cross-pollination and achieving optimal planting designs, this process has not been quantified previously in blueberry plantings. A novel method was developed to estimate the proportion of self- and cross-pollen transported by blueberry pollinators. The proposed technique requires a consistent difference in pollen size between two cultivars to predict the composition of a pollen mixture based on frequency distributions of pollen diameter. Vaccinium ashei Reade 'Brightwell' and 'Climax' were chosen for this study because they produce pollen tetrads of different size. Tetrad diameter and number were analyzed with a particle counter. The technique was validated by predicting the proportion of 'Brightwell' in pollen mixtures where the cultivar composition was known, and predicted and actual values were linearly correlated $(r=$ $0.995, P<0.0001)$. The technique was then applied to pollen samples extracted from the bodies of pollinators that were collected in a mixed 'Brightwell' and 'Climax' blueberry plot. Numbers of blueberry tetrads extracted per bumblebee (Bombus spp.) averaged 4595 and 797 in 2003 and 2004, respectively, which was considered adequate to make accurate predictions based on frequency distributions of tetrad diameter. The proportion of 'Brightwell' pollen carried by bumblebees changed with the phenology of the crop following an expected pattern, indicating that the method performed well under field conditions. This technique could potentially be used to quantify the likelihood for outcrossing and establish the effect of cultivar arrangements on pollen dispersion, as well as to examine pollen collection and manipulation, and cultivar preference by bees.

Cross-pollination is beneficial for optimum yields of many fruit crops that are either selfincompatible or suffer from inbreeding depression. Although blueberry species (Vaccinium section Cyanococcus) apparently have no pre-zygotic self-incompatibility mechanisms (El-Agamy et al., 1982; Garvey and Lyrene, 1987; Krebs and Hancock, 1988; Vander Kloet, 1991), limited self-fertility can occur as a consequence of early-acting inbreeding depression (Hokanson and Hancock, 2000; Krebs and Hancock, 1990; Krebs and Hancock, 1991).

Received for publication 11 May 2005. Accepted for publication 12 July 2005. A contribution of the University of Georgia Agricultural Experiment Stations, Georgia Station, Griffin. This research was supported, in part, by state and Hatch Act funds allocated to the Georgia Agricultural Experiment Stations.

${ }^{1}$ Research associate.

${ }^{2}$ Professor.

${ }^{3}$ Associate professor.

${ }^{4}$ Associate research scientist.
Cross-pollination is especially critical for adequate fruit set of Vaccinium ashei (rabbiteye blueberry) due to its low degree of self-fertility (El-Agamy et al., 1981; Garvey and Lyrene, 1987; Meader and Darrow, 1944). In blueberry species that are more self-fertile, such as $V$. corymbosum L. (highbush blueberry), crosspollination is still beneficial, resulting in larger fruit size and faster ripening rate (Meader and Darrow, 1947; Morrow, 1943).

Blueberries are xenogamous, bee-pollinated small fruit crops, and bee visitation is expected to result in cross-pollination. The information available, although scarce, suggests that pollen dispersion between cultivars may not be optimal. Vander Kloet and Lyrene (1987) indicated that geitonogamy (pollen transfer between flowers in the same plant) is likely to result as a consequence of the foraging behavior of blueberry pollinators. Moreover, Hancock et al. (1989) established that fruit size and seed number per berry declined with increasing distance from the source of cross-pollen. Pollen dispersion in rabbiteye blueberry has not been quantified previously, even though cross-pollination is critical for optimum yields.

In other fruit crops (mostly members of the Rosaceae subfamilies Pomoideae and Prunoideae), research has shown that pollen dispersion by bees can be quite limited. Fruit set tends to decline rapidly with increasing distance from pollinizer trees (Free, 1962; Free and Spencer-Booth, 1964; Milutinovic et al., 1996). Furthermore, pollen-mediated gene flow studies indicate that the distance of gene dispersal in fruit orchards is short and leptokurtic, with most of the gene flow occurring between adjacent cross-compatible trees (Jackson and Clarke, 1991; Kron et al., 2001; Wertheim, 1991).

Although genetic markers have been used successfully to infer patterns of pollen dispersion in self-incompatible species of the Rosaceae family, this approach may not be as practical for blueberries. On the one hand, the potential number of seeds per fruit in Vaccinium section Cyanococcus is high, ranging from 50 to 125 ovules per ovary (Palser, 1961). Therefore, paternity analyses would be labor-intensive. On the other hand, the blueberry self-infertility mechanism offers another limitation. Since there is no rejection of the microgametophyte at the pistil level following autogamous crosses, self-pollination can lead to fertilization and subsequent embryo abortion. Problems of low fruit set in blueberry crops could thus be caused by deposition of

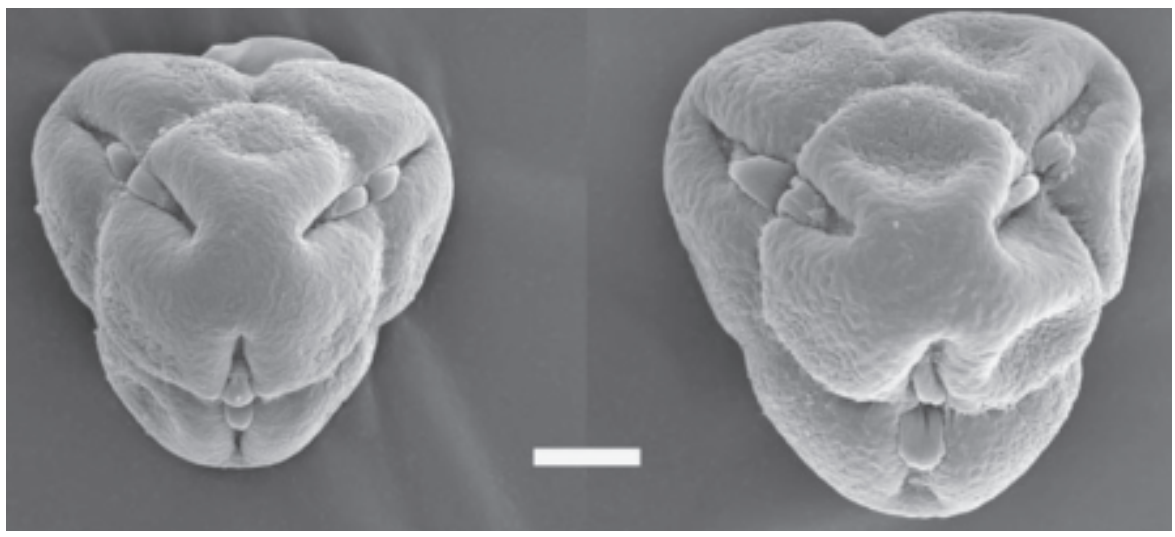

Fig. 1. Scanning electron micrographs of rabbiteye blueberry pollen tetrads from 'Climax' (left) and 'Brightwell' (right). Scale bar $=10 \mu \mathrm{m}$. 


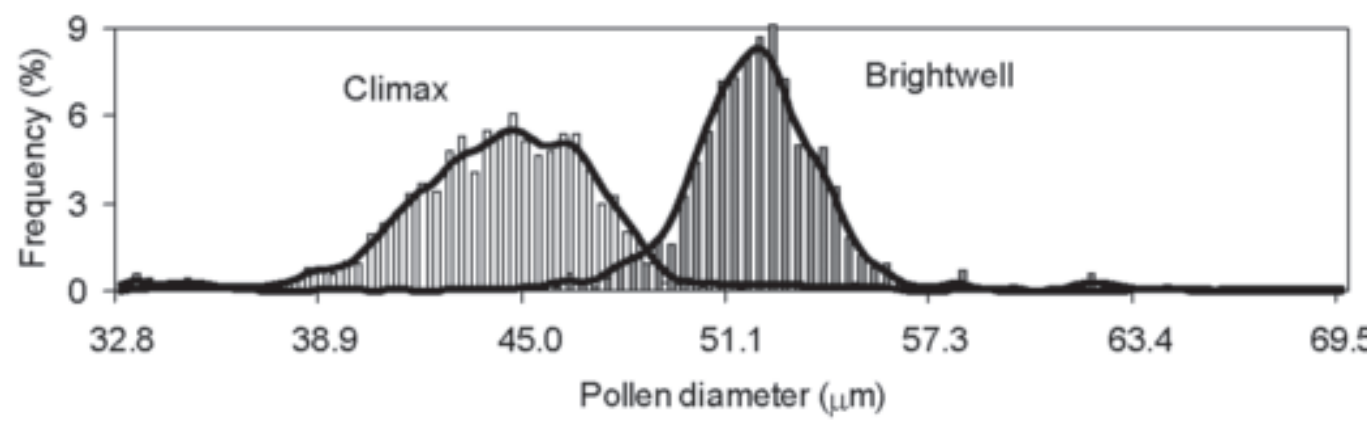

on the data. In practice, it is easier to maximize the log of the likelihood, which is equivalent to maximizing the likelihood function (Wackerly et al., 2002). The log-likelihood function for the pollen mixture was:

$\sum_{i=1}^{n} Y_{i}^{*} \log \left[(1-\beta)^{*} f_{c}\left(X_{i}\right)+\beta * f_{b}\left(X_{i}\right)\right]$

where $f_{b}(X)$ and $f_{c}(X)$ are the probability density functions for 'Brightwell' and 'Climax', respectively, $\beta$ is the proportion

Fig. 2. Frequency distribution of 'Climax' and 'Brightwell' tetrad diameters. Pollen samples of each cultivar were extracted from 50 flowers collected at the study site (see text). Bars represent observed frequencies and curves are smooth approximations of the probability density functions generated by kernel density estimation.

pollen loads that are rich in self-pollen. The ideal technique to study pollen dispersion in blueberry should allow quantification of the extent of selfing, but genetic marker-based techniques will underestimate the paternal contribution of self-pollen.

Knowledge of pollen dispersal is essential for maximizing cross-pollination and achieving optimal planting designs (Kron et al., 2001). Clearly, research is needed to understand the patterns of pollen dispersal in blueberry plantings, and a reliable method is required. In the present study, we describe a novel method, based on frequency distributions of pollen diameter, to estimate the proportion of selfand cross-pollen transported by bees as they forage on blueberry plants. In this technique, only the fraction of pollen carried dry and loose on the bodies of bees was extracted and analyzed (i.e., fraction available for pollination; Harder and Wilson, 1997; Thorp, 2000). Therefore, estimates of proportions of self- and cross-pollen transported by bees are an indirect assessment of bee-mediated pollen dispersion in blueberry plantings.

\section{Materials and Methods}

The technique developed requires a consistent difference in pollen size between two cultivars to predict the composition of a pollen mixture based on frequency distributions of pollen diameter. 'Brightwell' and 'Climax' rabbiteye blueberry plants were chosen for this study because their flowers produce pollen of different size (Fig. 1). Pollen size and number were analyzed with a particle counter.

Study site. Experiments were conducted in 2003 and 2004 in a mixed 'Brightwell' and 'Climax' rabbiteye blueberry plot located at the Georgia Experiment Station in Griffin. The plot was $33 \times 29 \mathrm{~m}$ in size. Plants were spaced at $3.7 \mathrm{~m}$ across rows and $1.5 \mathrm{~m}$ within rows. 'Brightwell' and 'Climax' plants were arranged in alternating rows (i.e., 1:1 planting). The study site was isolated from other sources of blueberry pollen. The closest blueberry plantings were $>800 \mathrm{~m}$ away.

General procedure for pollen size analysis. Pollen samples extracted from either blueberry flowers or pollinators were stored at room temperature in a solution containing $25 \%$ ethanol, $5 \%$ formalin, $4 \%$ acetic acid, and $66 \% \mathrm{dH}_{2} \mathrm{O}$ per volume. The pollen dispersal unit for $\mathrm{Vac}$ cinium species is a tetrad (Cockerham and Galleta, 1976). Tetrad diameter and number were measured with a Coulter counter (Multisizer II; Beckman Coulter, Fullerton, Calif.) using a $140-\mu \mathrm{m}$ aperture. Pollen suspensions were diluted in Isoton II diluent (Beckman Coulter) just before particle analysis. A magnetic stirrer was used to maintain uniform distribution of tetrads within the saline solution. Pollen grains from five to six 0.5 -mLaliquots of continuously stirring suspension were sized and counted per sample. Raw data consisted of absolute accumulated frequencies of tetrads in classes of diameter at $0.38-\mu \mathrm{m}$ intervals. The precision of the measurements was monitored by adding $20-\mu \mathrm{m}$ polystyrene latex particles (Beckman Coulter) to every analyzed sample.

Prediction of cultivar proportions in pollen mixtures. Proportions of 'Brightwell' and 'Climax' tetrads in pollen mixtures were predicted using the observed frequencies of pollen diameter. A smooth approximation to the probability density function for 'Brightwell' and 'Climax' pollen diameter was generated using kernel density estimation. The kernel density estimator was:

$$
\hat{f}_{h}(x)=\frac{1}{h \sum Y_{i}} \sum Y_{i} K\left(\frac{x-X_{i}}{h}\right)
$$

where $h$ is the bandwidth, $K$ is the kernel function, $X$ is the midpoint of the $i$ th diameter class, and $Y$ is the number of observations in the $i$ th diameter class. The general form of the kernel function is given by Härdle (1991). Appropriate kernel functions are symmetric about the vertical axis, positive, and integrate to 1 . The kernel function chosen for this analysis was the normal kernel:

$K(x)=\frac{\exp \left(\frac{-x^{2}}{2}\right)}{\sqrt{2 \pi}}$

Estimated probability density functions based on this method gave a good fit to the data (Fig. 2).

The proportion of 'Brightwell' in the pollen mixture was estimated using the maximum likelihood method. The likelihood function is the density function based on the observed data (assuming that the data are independent) but viewed as a function of the density's parameters. The likelihood function is maximized over the parameters to produce a maximum likelihood estimate of those parameters, based of 'Brightwell' in the pollen mixture, and $X_{i}$ and $Y$ are as defined above. Then, the proportion of 'Climax' in the pollen mixture was estimated by the difference $1-\beta$.

The program to construct the kernel density estimates of the distributions of 'Brightwell' and 'Climax' pollen diameters, as well as to compute the maximum likelihood estimate of $\beta$, was written in the language $F$ (Brainerd et al., 1996), a cheap-ware subset of Fortran (Fortran Co., Tucson, Ariz.), which can be compiled under most modern Fortran environments. The numerical optimization algorithm used to compute the maximum likelihood estimate of $\beta$ was the quasi-Newton algorithm (Nash, 1990).

Validation of the model. The model was validated by predicting the proportion of 'Brightwell' in pollen mixtures where the cultivar composition was known.

Pollen tetrads were extracted from samples of 50 flowers collected at the study site from either 'Brightwell' or 'Climax' plants. In 2003, six replications of each cultivar were collected on 4 Apr. In 2004, one replication per cultivar was collected on five different dates (24 Mar., 27 Mar., 2 Apr., 5 Apr., and 12 Apr.). Pollen samples for each replicate were stored in vials with $20 \mathrm{~mL}$ of fixative solution as described earlier. The absolute tetrad concentration in each 20-mL suspension was estimated by counting the number of pollen grains in four aliquots using the previously described particle counter. Then, aliquots from a pair of 'Brightwell' and 'Climax' pollen samples (with a known tetrad concentration) were combined to achieve five pollen mixtures containing $20 \%, 40 \%, 50 \%$, $60 \%$, and $80 \%$ of 'Brightwell'. These mixtures were analyzed with the particle counter following the procedure described previously.

The probability density function for diameter of pure pollen was estimated by kernel density estimation from observed frequency distributions as described above. Data from mixed pollen samples were analyzed using the density functions obtained from the pair of 'Brightwell' and 'Climax' samples used to assemble the mixture. The percentage of 'Brightwell' in the mixture was predicted by the maximum likelihood method.

Analysis of pollen extracted from bees. Bumblebees (Bombus spp.) and honeybees (Apis mellifera L.) were collected at the study site in 2003 and 2004. Native bumblebee queens were common at the blueberry plot during the entire blueberry flowering season. A honeybee colony was placed near the blueberry plot to ensure adequate visitation by $A$. mellifera . 


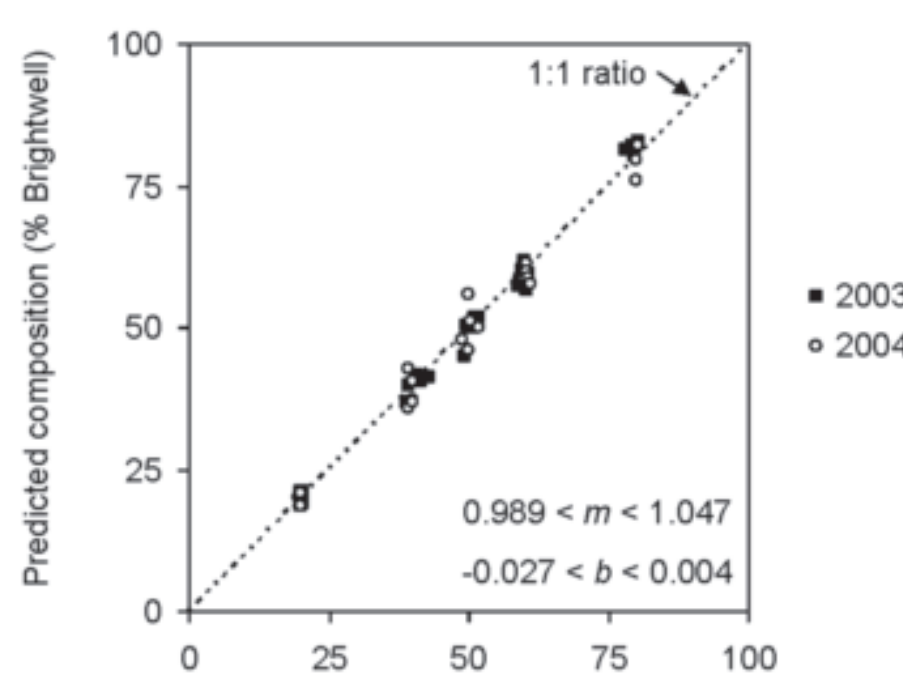

Actual composition (\% Brightwell) bees $[$ Xylocopa virginica (L.)] were also present at the study site, they were not included in this study because of their questionable value as blueberry pollinators (Cane and Payne, 1991).

Pollinators were collected as they visited 'Brightwell' and 'Climax'plants. Bees were caught with an insect net or directly using killing jars containing chloroform. The short exposure to chloroform was effective enough to quickly anesthetize

Fig. 3. Predicted versus actual composition of 'Brightwell' and 'Climax' pollen mixtures $(\mathrm{n}=55)$. Confidence intervals for the slope $(m)$ and the y-axis intercept $(b)$ are also presented $(\alpha=0.05)$.

The number of bumblebees and honeybees collected was 51 and 22 in 2003, respectively, and 126 and 60 in 2004. Although carpenter

Table 1. Mean number of blueberry pollen tetrads extracted from the bodies of bumblebees and honeybees foraging on a mixed 'Brightwell' and 'Climax' rabbiteye blueberry plot in 2003 and 2004

\begin{tabular}{lcc}
\hline & \multicolumn{3}{c}{$\begin{array}{c}\text { Total tetrads per } \\
\text { individual (no.) }\end{array}$} \\
\cline { 2 - 3 } Pollinator & 2003 & 2004 \\
\hline Bumblebee (queen) & $4595 \pm 1032(51)^{z}$ & $797 \pm 67(126)$ \\
Honeybee (worker) & $167 \pm 41 \quad(22)$ & $70 \pm 10(60)$ \\
\hline
\end{tabular}

${ }^{2}$ Values are means $\pm \mathrm{SE}$, with sample sizes (individuals collected) in parentheses.
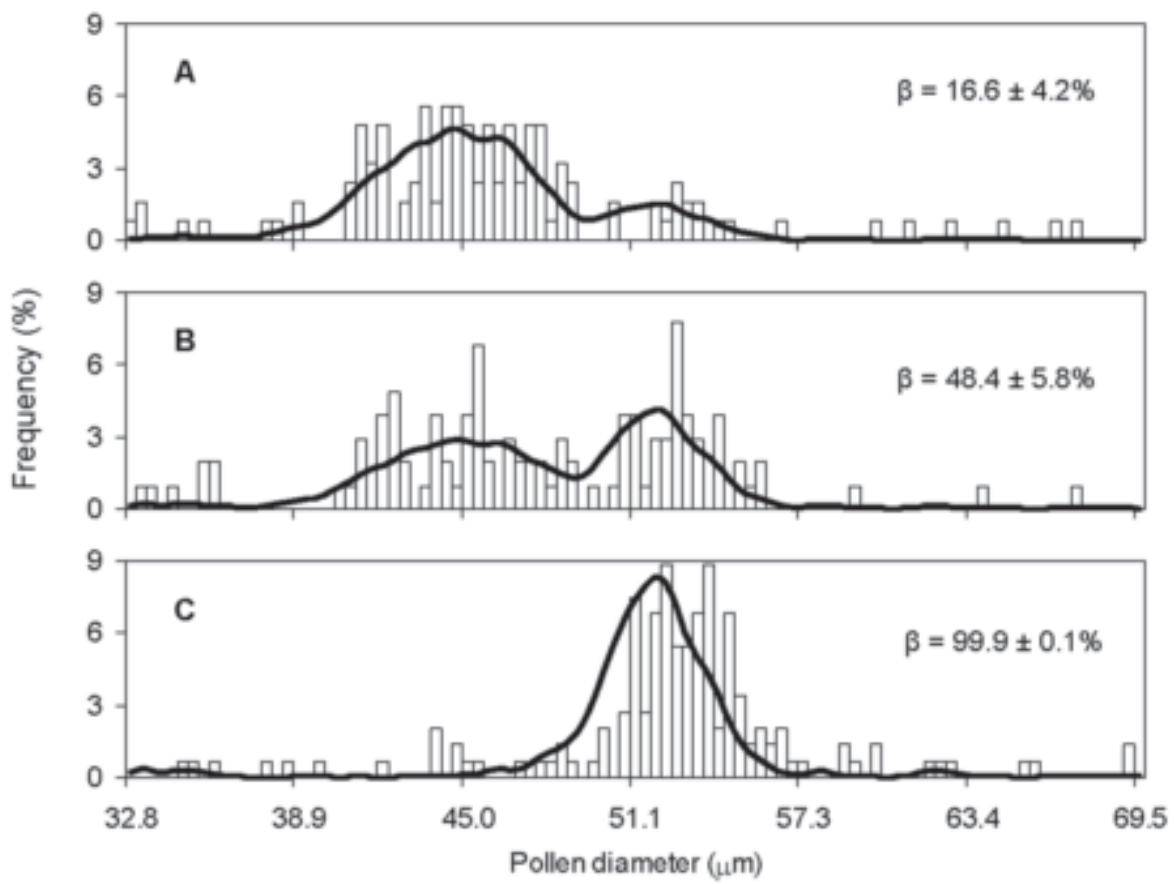

Fig. 4. Diameter frequency distributions of blueberry tetrads extracted from individual bumblebees collected from 'Climax' (A and B) and 'Brightwell' (C) plants. Curves fitted using the maximum likelihood method and the predicted percentage of 'Brightwell' pollen $(\beta \pm \mathrm{SE})$ are also presented. For probability density functions of pure samples of 'Brightwell' and 'Climax', see Fig. 2. carried pollen in the corbicula (pollen basket in the hind legs), the corbicular pollen loads were removed using fine-pointed forceps before adding the solution to the vial. This was done because pollen carried in these pollen-transporting areas, moistened with nectar, is unavailable for pollination (Harder and Wilson, 1997; Thorp, 2000). Pollen tetrads were extracted from the bodies of bees by shaking the vials for $30 \mathrm{~min}$ at $270 \mathrm{rpm}$ using a G10 Gyrotory shaker (New Brunswick Scientific; Edison, N.J.). Bees were then taken out of the solution and pollen was kept inside of the vial until analysis with the particle counter. In addition to extracting pollen from bees, pollen samples were also collected directly from flowers to be used as standard. A single pollen sample per cultivar was extracted on each sampling day from 50 flowers randomly collected in the experimental plot.

The diameter of blueberry tetrads carried by the bees was used to predict the proportion of each cultivar in the pollen extract, in a way similar to that described for pollen mixtures in the validation of the model. Probability density functions were estimated from pure pollen samples extracted from flowers of each cultivar. These densities were used to analyze the data from all the bees collected on that particular sampling day.

\section{Results and Discussion}

Validation of the model. The predicted proportion of 'Brightwell' was linearly related to the actual proportion in the pollen mixture $(r=0.995, P<0.0001, \mathrm{n}=55$; Fig. 3$)$. At $\alpha=$ 0.05 , the Y-axis intercept and the slope were not statistically different from 0 and 1 , respectively. These results indicate that unbiased predictions of the proportion of each cultivar in the pollen mixture can be made using diameter frequency distributions.

Analysis of pollen extracted from bees. The presence of pollen from sources other than blueberry represented the major potential problem for applying this method in the field. Observations of pollen extracts under the microscope confirmed the presence of pollen from other plant species, which was consistent with previous reports (Cane and Payne, 1988; Delaplane, 1995; Dogterom and Winston, 1999; Vander Kloet, 1976). Two monads from unidentified plant species were the most common foreign pollen found in the collected specimens. However, these two pollen types were smaller than blueberry tetrads, with a mean diameter $( \pm$ SD) of $18 \pm 1 \mu \mathrm{m}$ and $30 \pm 2 \mu \mathrm{m}$. Therefore, no interference from foreign pollen was expected within the range of diameter of blueberry tetrads.

The average number of blueberry tetrads extracted per pollinator is shown in Table 1 . Tetrad numbers per bumblebee and honeybee were significantly different. Bumblebee pollen numbers were 11 to 28 times those of honeybees. The actual number of tetrads sized and counted in a sample extracted from the body of an average bumblebee was about 100 to $120(\mathrm{n}=800$ tetrads suspended in 20 $\mathrm{mL}$; five to six $0.5-\mathrm{mL}$ aliquots counted per 


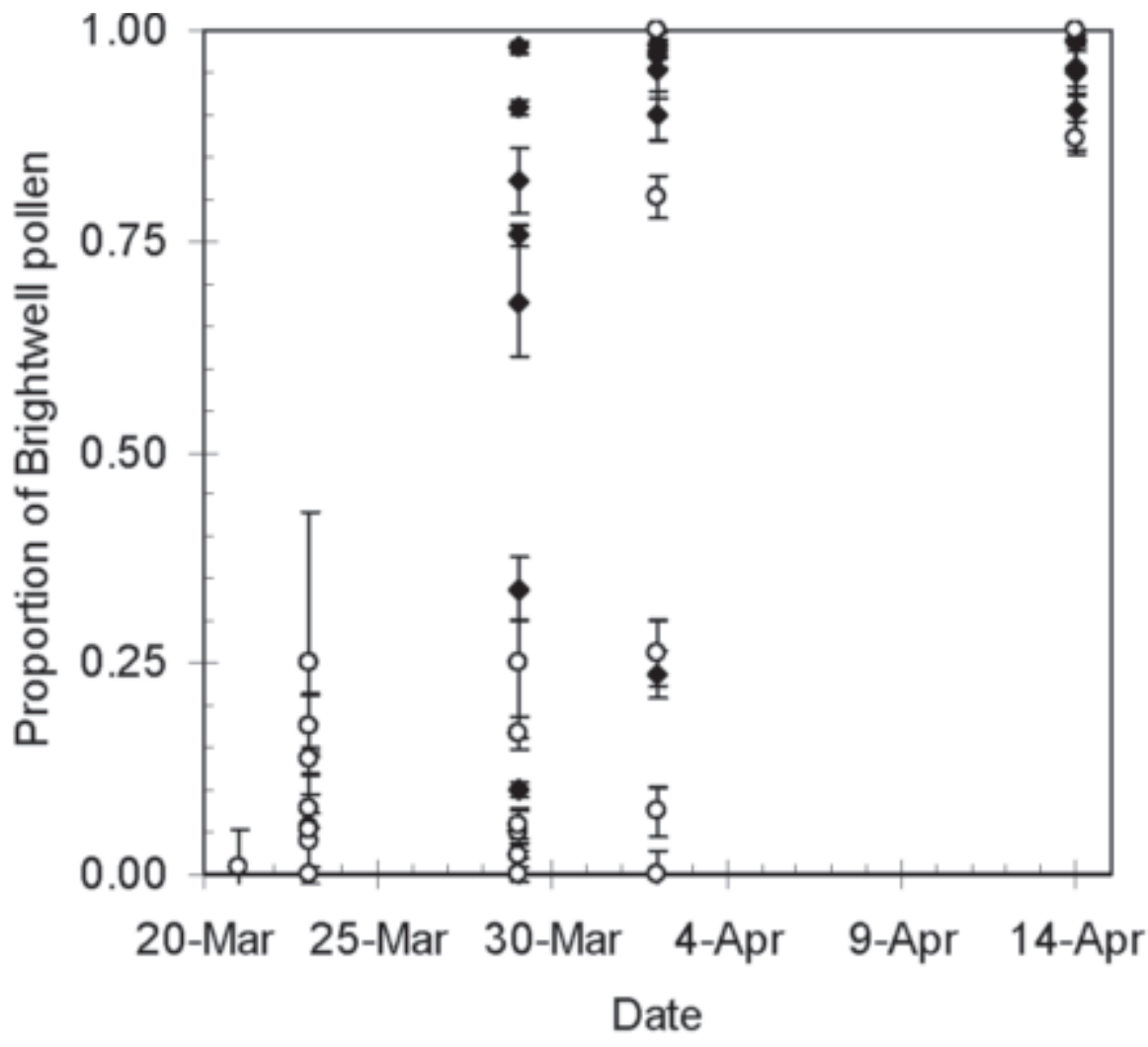

Specimen collected on • Brightwell o Climax

Fig. 5. Proportion of 'Brightwell' pollen $( \pm \mathrm{SE})$ carried by individual bumblebees $(\mathrm{n}=51)$ collected from 'Brightwell' $(\downarrow)$ or 'Climax' $(\bigcirc)$ blueberry plants in Spring 2003. Dates of 50\% bloom were 29 Mar. for 'Climax' and 4 Apr. for 'Brightwell'.

sample). Bumblebees were considered to be a good model species for studying pollinator activity in blueberry plantings using the proposed technique. In contrast, the number of tetrads sized and counted in samples from honeybees was too low to obtain accurate estimates based on diameter frequency distributions. It has been reported previously that honeybees can carry pollen grains in numbers ranging from several thousands to a few million (Free, 1970). The small number of blueberry tetrads extracted per honeybee in this study may be due to their incapacity to sonicate the poricidally dehiscent anthers of blueberry flowers (Buchmann, 1983). Another important contributing factor was the presence of carpenter bees at the study site. These bees cut slits at the base of the tubular corolla of blueberry flowers to imbibe nectar, and honeybees readily visit these pierced flowers through the robbery holes made by carpenter bees, resulting in illegitimate honeybee visits (Dedej and Delaplane, 2004; Delaplane and Mayer, 2000). During illegitimate visits, honeybees act as secondary nectar thieves and avoid the flower opening (bypassing the androecium), which limits the amount of pollen that they can collect from the flower. High numbers of pierced corollas were present at the study site during the entire flowering season of 2003 and 2004, resulting in many such "illegitimate" visits by honeybees.

Frequency distributions of pollen diameter and predicted proportions of 'Brightwell' for selected bumblebees are shown in Fig. 4. Curves estimated with the maximum likelihood method gave a good fit to the data.

'Climax' plants bloom earlier than those of 'Brightwell', which gave an opportunity to determine if the predicted cultivar proportions changed as the season progressed (Fig. 5). Specimens collected at the beginning of the season in 2003 carried small proportions of 'Brightwell' pollen, which was expected considering that very few 'Brightwell' flowers were open at that time. Conversely, all bees collected on the last sampling day carried almost a pure load of 'Brightwell' pollen. Bees collected between 29 Mar. and 2 Apr. carried mostly pollen from the cultivar where the specimen was foraging. Similar trends were observed in 2004 (data not shown). These results indicate that the method worked well under field conditions.

Previous attempts have been made to identify pollen grains by cultivar in pollen loads carried by bees (Jackson and Clarke, 1992; Mittler, 1962; Vezvaei and Jackson, 1997). The pollen extracting procedure used in the present study differed from previous work in that corbicular pollen loads were excluded. Therefore, pollen samples extracted from bumblebees were representative of the fraction of blueberry tetrads available for pollination. Pollen cultivar proportions can thus be considered as an estimate of the likelihood for 'Brightwell' or 'Climax' pollen to be deposited on the stigma.
In summary, a novel method using frequency distributions of pollen diameter to quantify transport of self- and cross-pollen by blueberry pollinators was developed. The technique requires a consistent difference in pollen diameter between two cultivars, which may restrict its range of application. Preliminary evaluations, limited to a few rabbiteye cultivars, indicated that 'Brightwell' and 'Climax' had suitable extreme values of tetrad diameter. Data on tetrad diameter for other blueberry species would be needed to identify suitable pairs of cultivars to study pollen dispersion using this technique. Other potential problems such as interference from foreign pollen or undesired interactions among bee species (e.g., presence of carpenter bees) could be overcome by conducting experiments under a cage or net-house. The proposed technique could potentially be used to quantify the likelihood for outcrossing and establish the effect of cultivar arrangements on pollen dispersion, as well as to examine pollen collection and manipulation and cultivar preference by bees. Findings obtained by applying this method under field conditions are presented in a companion paper (Brevis and NeSmith, 2005).

\section{Literature Cited}

Brainerd, W.S., C.H. Goldberg, and J.C. Adams. 1996. Programmer's guide to F: F95 version. Fortran Co., Tucson, Ariz.

Brevis, P.A. and D.S. NeSmith. 2005. Transport of cross-pollen by bumblebees in a rabbiteye blueberry planting. HortScience 40(7):2007-2010.

Buchmann, S.L. 1983. Buzz pollination in angiosperms, p. 73-113. In: C.E. Jones and R.J. Little (eds.). Handbook of experimental pollination biology. Van Nostrand Reinhold, New York.

Cane, J.H. and J.A. Payne. 1988. Foraging ecology of the bee Habropoda laboriosa (Hymenoptera: Anthophoridae), an oligolege of blueberries (Ericaceae: Vaccinium) in the southeastern United States. Ann. Entomol. Soc. Amer. 81:419-427.

Cane, J.H. and J.A. Payne. 1991. Native bees pollinate rabbiteye blueberry. V. Biennial S.E. Blueberry Conf. 5:53-57.

Cockerham, L.E. and G.J. Galleta. 1976. A survey of pollen characteristics in certain Vaccinium species. J. Amer. Soc. Hort. Sci. 101:671-676.

Dedej, S. and K.S. Delaplane. 2004. Nectar-robbing carpenter bees reduce seed-setting capability of honey bees (Hymenoptera: Apidae) in rabbiteye blueberry, Vaccinium ashei, 'Climax'. Environ. Entomol. 33:100-106.

Delaplane, K.S. 1995. Bee foragers and their pollen loads in South Georgia rabbiteye blueberry. Amer. Bee J. 135:825-826.

Delaplane, K.S. and D.F. Mayer. 2000. Crop pollination by bees. CAB Intl. Publ., Oxon, U.K

Dogterom, M.H. and M.L. Winston. 1999. Pollen storage and foraging by honey bees (Hymenoptera:Apidae) in highbush blueberries (Ericaceae), cultivar Bluecrop. Can. Entomol. 131:757-768.

El-Agamy, S.Z.A., W.B. Sherman, and P.M. Lyrene. 1981. Fruit set and seed number from self- and cross-pollinated highbush $(4 \mathrm{x})$ and rabbiteye (6x) blueberries. J. Amer. Soc. Hort. Sci. 106:443-445.

El-Agamy, S.Z.A., W.B. Sherman, and P.M. Lyrene. 1982. Pollen incompatibility in blueberries ( Vaccinium spp.). J. Palynol. 18:103-112.

Free, J.B. 1962. The effect of distance from pollinizer varieties on the fruit set on trees in plum and apple orchards. J. Hort. Sci. 37:262-271. 
Free, J.B. 1970. Insect pollination of crops. Academic Press, London.

Free, J.B. and Y. Spencer-Booth. 1964. The effect of distance from pollinizer cultivars on the fruit set of apple, pear and sweet-cherry trees. J. Hort. Sci. 39:54-60.

Garvey, E.J. and P.M. Lyrene. 1987. Self incompatibility in 19 native blueberry selections. J. Amer. Soc. Hort. Sci. 112:856-858.

Hancock, J.F, S.L. Krebs, M. Sakin, and T.P. Holtsford. 1989. Increasing blueberry yields through mixed variety plantings. Mich. State Hort. Soc. Annu. Rpt. 119:130-133.

Harder, L.D. and W.G. Wilson. 1997. Theoretical perspectives on pollination. Acta Hort. 437:83-101.

Härdle, W. 1991. Smoothing techniques: With implementation in S. Springer, New York.

Hokanson, K. and J. Hancock. 2000. Early-acting inbreeding depression in three species of Vaccinium (Ericaceae). Sex. Plant Reprod. 13:145-150.

Jackson, J.F. and G.R. Clarke. 1991. Gene flow in an almond orchard. Theor. Appl. Genet. 82:169-173.

Jackson, J.F. and G.R. Clarke. 1992. Patterns of bee visitation to flowers of almond cultivars in an orchard as determined by molecular genetic markers analysis of pollen in the "pollen basket", p. 441-444. In: E. Ottaviano, D.L. Mulcahy, M. Sari-Gorla, and G.B. Mulcahy (eds.). Angiosperm pollen and ovules. Springer, New York.
Krebs, S.L. and J.F. Hancock. 1988. The consequences of inbreeding on fertility in Vaccinium corymbosum L. J. Amer. Soc. Hort. Sci.113:914-918.

Krebs, S.L. and J.F. Hancock. 1990. Early-acting inbreeding depression and reproductive success in the highbush blueberry, Vaccinium corymbosum L. Theor. Appl. Genet. 79:825-832.

Krebs, S.L. and J.F. Hancock. 1991. Embryonic genetic load in the highbush blueberry, Vaccinium corymbosum (Ericaceae). Amer. J. Bot. 78:1427-1437.

Kron, P., B.C. Husband, P.G. Kevan, and S. Belaoussoff. 2001. Factors affecting pollen dispersal in high-density apple orchards. HortScience 36:1039-1046.

Meader, E.M. and G.M. Darrow. 1944. Pollination of the rabbiteye blueberry and related species. Proc. Amer. Soc. Hort. Sci. 45:267-274.

Meader, E.M. and G.M. Darrow. 1947. Highbush blueberry ollination experiments. Proc. Amer. Soc. Hort. Sci. 49:196-204.

Milutinovic, M., G. Surlan-Momirovic, and D. Nikolic. 1996. Relationship between pollinizer distance and fruit set in apple. Acta Hort. 423:91-94.

Mittler, T.E. 1962. Preliminary studies on apple pollination, p. 173-178. Proc. I Intl. Symp. Pollination.

Morrow, E.B. 1943. Some effects of cross-pollination versus self-pollination in the cultivated blueberry. Proc. Amer. Soc. Hort. Sci. 42:469-472.

Nash, J.C. 1990. Compact numerical methods for computers: Linear algebra and function minimization. 2nd ed. Adam Hilger, Bristol, U.K.

Palser, B.F. 1961. Studies of floral morphology in the Ericales. V. Organography and vascular anatomy in several United States species of the Vacciniaceae. Bot. Gaz. 123:79-111.

Thorp, R.W. 2000. The collection of pollen by bees. Plant Syst. Evol. 222:211-223.

Vander Kloet, S.P. 1976. Nomenclature, taxonomy, and biosystematics of Vaccinium section Cyanococcus (the blueberries) in North America. I. Natural barriers to gene exchange between Vaccinium angustifolium Ait. and Vaccinium corymbosum L. Rhodora 78:503-515.

Vander Kloet, S.P. 1991. The consequences of mixed pollination on seed set in Vaccinium corymbosum. Can. J. Bot. 69:2448-2454.

Vander Kloet, S.P., and P.M. Lyrene. 1987. Selfincompatibility in diploid, tetraploid, and hexaploid Vaccinium corymbosum. Can. J. Bot. 65:660-665

Vezvaei, A. and J.F. Jackson. 1997. Gene flow by pollen in an almond orchard as determined by isozyme analysis of individual kernels and honey bee pollen loads. Acta Hort. 437:75-81.

Wackerly, D.D., W. Mendenhall, III, and R.L. Scheaffer. 2002. Mathematical statistics with applications. 6th ed. Duxbury Press, Pacific Grove, Calif.

Wertheim, S.J. 1991. Malus cv. Baskatong as an indicator of pollen spread in intensive apple orchards. J. Hort. Sci. 66:635-642. 